\title{
Analysis of Water Resources Vulnerability Assessment Tools
}

\author{
Kanga Idé Soumaila ${ }^{1}$, Albachir Seydou Niandou ${ }^{2}$, Mustapha Naimi ${ }^{1}$, Chikhaoui Mohamed ${ }^{1}$ and Keith Schimmel ${ }^{2}$ \\ 1. Soil and Water Management Laboratory, Department of Natural Resources and Environment, Hassan II Institute of Agronomy \& \\ Veterinary Medicine, Rabat 10101, Morocco \\ 2. Applied Science and Technology, North Carolina Agricultural and Technical State University, Greensboro, NC 27411, USA
}

\begin{abstract}
Water resources face many pressures and stresses around the world. Assessing the vulnerability of water resources is, therefore, increasingly an essential practice in water resources management. Several studies of water resources vulnerability have been carried out around the world during the last three decades. Thus, the main objective of this study was to analyze water resources vulnerability assessment tools and identify the methodological trend of water resources vulnerability assessment at the local level in existing literature. To achieve this objective, the Preferred Reporting Items for Systematic Reviews and Meta-Analyses (PRISMA) method has been applied to include or exclude articles. Articles on water vulnerability numbering 374 were preselected in the ScienceDirect and the Google Scholar databases. Only 32 out of the 374 articles met the inclusion criteria defined for the analysis. The results show that China (21.9\%), U.S.A. (9.4\%) and Canada (6.3\%) are the most active countries publishing water resources vulnerability assessments. Some 191 vulnerability indicators from the 32 articles were classified into five categories of factors: physical factors (33.5\%), socio-economic factors (28.3\%), environmental or eco-environmental factors (25.1\%), institutions and governance factors $(7.3 \%)$ and infrastructure factors (5.8\%). This study shows that almost half of the studies (47\%) considered all five categories of factors, $9.4 \%$ considered four categories of factors, $6.3 \%$ considered three categories of factors, $28 \%$ used two types of factors and $9.4 \%$ considered only one category. Researchers have used several methods to assess water resources vulnerability: overlay and index methods (59.4\%), process-based models (12.5\%), statistical methods (9.4\%), overlay and index methods plus process-based model (9.4\%), overlay and index methods plus statistical methods (6.3\%) and statistical methods plus process-based models (3.1\%). Geographic information system (GIS) is an important tool in assessing the vulnerability of water resources with almost $60 \%$ of the studies using it at some stage of the assessment. In recent years, there is an increasing trend toward conceptualizing the vulnerability of water resources in a holistic way.
\end{abstract}

Key words: Water vulnerability, water resources management, water vulnerability assessment tools.

\section{Introduction}

Water resources face many pressures and intense stresses around the world. While rainfall will increase in some parts of the world and will decrease in others [1], the impacts of population growth, pollution, agricultural activities and industrial activities are disrupting and threatening water resources [2]. In other words, increased demands for water due to agricultural and industrial activities, water pollution, and extreme weather events caused by climate change are at the root causes of disturbances [3]. The

Corresponding author: Keith Schimmel, associate professor, research field: environmental engineering.
Intergovernmental Panel on Climate Change (IPCC) predicts that current growth in greenhouse gases will directly affect the global hydrological cycle and impact water availability and demand [4].

In the face of these problems, methods or tools for assessing the vulnerability of water resources have multiplied to assist decision-making [5]. Since the 1960s, policy makers have shown interest in developing tools for classifying water resources in terms of uses [6], and most of the studies focused on the vulnerability of ground water [7]. Prior studies focused on the physical component of water vulnerability [8-10] or on water availability [11-14]. The vulnerability of water resources, however, has 
many facets so that its evaluation, to be useful to policy makers and water managers, must be holistic [15]. Since the 2000s, the methods developed in the context of water management consider several aspects: indices of water poverty [16-18] and multidimensional methods of water vulnerability [1, 4, 19-23].

Water resource vulnerability assessment is increasingly used in water management around the world [15]. However, it is not a simple analysis because of the complex nature of the interactions that exist between the different components of the water resources system. One of the biggest challenges since the advent of water vulnerability assessment has been how to define the term "vulnerability", because the notion of vulnerability is relative and difficult to quantify, and there has not a single definition accepted by all. Therefore, there is not a universal method of vulnerability assessment [4, 24, 25]. Studies done over decades present several definitions of the term and their definitions are based on the environmental problems encountered, the objectives of the study, and the availability of data on the factors considered [1, 21, 22, 26-28]. With the advent of climate change, researchers [1, 22, 27, 28] conceptualized the water resources vulnerability with physiographic and socio-economic parameters, including natural factors (physical and ecological), social and economic dimensions and water institutions and governance. In this context, it is very difficult to know what factors are used in a water vulnerability assessment and what methodological approach is needed to undertake the assessment. Therefore, the main objective of this study was to identify the vulnerability factors of water resources and the methodological trends of water vulnerability assessment at the local level in the international literature on water resources.

\section{Water Vulnerability Assessment Tools and Conceptualization}

\subsection{Vulnerability}

The notion of vulnerability is increasingly widespread in different scientific disciplines. Janssen et al. [29] analyzed 2,286 publications between 1967 and 2005 and found 939 references in scientific articles that use the word vulnerability as a keyword only on global change research. Although the term "vulnerability" has become very popular in recent studies, there are several definitions of the term, depending on the field, the objective of the study and the environmental problems encountered. Turner et al. [30] state that the general use of the term "vulnerability" refers to the ability of a system to be injured, i.e., the degree to which the system is likely to suffer damage as a result of exposure to a hazard. The IPCC [31] defines vulnerability as "the degree to which a system is able or unable to cope with the adverse effects of climate change, including climate variability and extreme effects". Vulnerability is a function of the character, magnitude and rate of climate change to which a system is exposed, its sensitivity and its adaptive capacity. Hinkel et al. [32] criticized the definition and found it vague and difficult to operationalize. Yet in recent vulnerability studies, this definition is the most widely used, since it corresponds to the multidimensional nature of vulnerability. Gain et al. [4] argue that this definition is one of the most generic and could be considered as a basis for further refinement in the conceptualization of vulnerability in the field of sustainable development and the ecological-social system.

Birkmann [33] presented a conceptual framework for vulnerability assessment in which vulnerability is seen on two faces that can be summarized as internal and external. The internal face is linked to adaptation and involves the ability to anticipate, cope, resist and recover from the impact of a risk. The external face refers to the exposure to risks. In the area of water resource vulnerabilities, researchers define the term in relation to the physical, biological, socio-economic and ecological conditions of the environment, the policy decisions and the regulatory framework for water protection [7, 34, 35]. 
2.2 Conceptual Framework for Water Resources Vulnerability Assessment and Vulnerability Factors

In all water resource vulnerability research, the vulnerability of water resources is defined in relation to internal and/or external factors. The conceptualization in water resources vulnerability assessment is based on the choice of factors considered relevant. The factors used to define the vulnerability of water resources depend on the study concept (related environmental problem), the study area and the research objective. Winograd et al. [36] argue that there is no universal set of indicators that is equally applicable in all cases and the selection of indicators should be closely linked to the study objectives and the environmental issues addressed. In most cases, the assessment of water resource vulnerability has only one main objective, which is water resource management. However, the concept of water resource management may have different connotations.

Hooper [37] argues that the old approach to water resources management was hydro-centric and single-sector oriented, whereas a watershed is a complex system based on a complex interrelation between the hydrological and geomorphological characteristics of the basin and its rivers and streams. In addition to these physical characteristics, it is also necessary to add the socio-economic characteristics of the basin. The emergence of the concept of integrated water resources management has brought to light various factors. Füssel [25] reports four relevant groups of vulnerability factors to disaster reduction:

- The physical factors that describe the exposure of vulnerable elements in a region;

- Economic factors describing the economic resources of individuals, population groups and communities;

- Social factors that describe the non-economic factors that determine the well-being of individuals, population groups and communities, such as educational attainment, security, access to basic human rights and good governance;

- Environmental factors describing the state of the environment in a region.

Plummer et al. [15] have systematically reviewed 50 water resources vulnerability assessment tools and identified 710 indicators used, divided into two groups of factors, biophysical and social factors. Alessa et al. [28] conceptualized an index called the "Arctic Water Resources Vulnerability Index (AWRVI)" at the community and/or watershed level that integrates the entire socio-ecological system including five physical factors with 18 indicators and four social factors with eight indicators.

Several authors conceptualize vulnerability in different ways, but this difference lies in the fact that the factors that influence the risk of vulnerability of water resources are numerous and require a relevant choice by scientists in conceptualizing vulnerability. IPCC [31] points out that many specialists in different fields have conceptualized vulnerability according to their areas of intervention, based on the objectives to be achieved and the methodologies applied. Zarafshani et al. [38] add that these differences in the conceptualization of vulnerability, with multiple choices of factors, prevent a common methodological approach to vulnerability assessment. Tuner et al. [30] argue that to assess and conceptualize vulnerability, it is first necessary to identify multiple disturbances and interactions of stress factors, exposure level, sensitivity and adaptive capacity of the system. Wang et al. [7] see the assessment of water resources vulnerability from the perspective that a water resources system can be damaged by natural factors and human activity and add that a water resources system itself is unstable and sensitive to external factors. It is, therefore, necessary to assess the so-called intrinsic and specific vulnerability, i.e., to assess the disturbances of the characteristics specific to the system and those caused by the external environment. The difference in methodologies lies in the conceptualization that depends on the framework 
in which the vulnerability was previously defined.

2.3 Choice, Weighting, Normalization and Aggregation of Factors

\subsubsection{The Choice of Factors}

The choice of factors is one of the most important steps because the relevance of the assessment of water vulnerability can be judged in this step. The Organization for Economic Cooperation and Development (OECD) [39] believes that the strengths and weaknesses of a composite index depend largely on the quality of the indicators considered. The selection of variables or factors or indicators is a difficult exercise and must be done in a serious way. The choice of factors with their indicators and the conceptualization of vulnerability are probably the most important steps in a vulnerability assessment. The choice of relevant factors must be carefully and seriously addressed with the help of all stakeholders involved in the water sector through surveys [15]. The relevance of the final water vulnerability index can be judged mainly from the choice of factors, and each factor can have at least two indicators to give an integrated dimension to the vulnerability assessment.

Several methods are used to select factors. Gain et al. [4] report two general approaches to choosing factors, with these approaches also cited in Hinkel et al. [32] and Adger [40]: the deductive approach, which is based on a theoretical understanding of the interrelationships between the components, and the inductive approach, which is based on the statistical relationships between a large numbers of variables. For the inductive approach, multi-variable analysis and main component analysis are used to reduce the number of variables considered [32]. Mazziotta and Pareto [41] report that statistical methods are used to calculate the correlation between factors and to take the least correlated factors, thus reducing redundancy. Other methods are also used to select the factors: questionnaire from water management experts, Delphi technique, literature review (LR) and empiric approach.

\subsubsection{Weighting of Factors}

Factors do not have the same contributing forces with respect to the vulnerability of water resources. It is therefore necessary to assign their relative weights according to their relative strengths. Statistical methods and stakeholder surveys allow weights to be assigned to the different factors. The German corporation for international cooperation (GIZ) [42] argues that the weights assigned to the different indicators (or components of vulnerability) can come from existing literature, information provided by stakeholders, or expert judgments. OECD [39] lists several methods for weighting indicators:

- Statistical methods: principal component analysis;

- Participatory methods: according to GIZ [42], participatory methods are quite practical and transparent ways of weighting factors. OECD [39] considers that the main advantage of this method is its transparency, short duration and relatively direct nature;

- "Budget Allocation Process (BAP)": the principle is to ask water management experts, for example, to allocate a budget of 100 points to the different factors based on their experience and their vision of the relative importance of each factor in relation to the vulnerability of water resources. OECD [39] believes that the choice of experts should be representative by bringing together experts representing a wide range of knowledge and experience to ensure that an appropriate weighting system is put in place;

- Public opinion: same principle as BAP, but the assignment of weights here is addressed to the public. This is an opinion poll addressed to the public, focusing on the notion of concern [39].

Methods such as expert opinion or Delphi technique, deductive approach, LR, empiric approach and analytic hierarchy process (AHP) are also used to weight factors. 


\subsubsection{Normalization of Factors}

The purpose of normalizing factors data is to unify the dimensions of the different components of vulnerability into dimensionless values to aggregate them into a composite index. This operation consists in transforming the data of each factor into values without units. In the water resources literature, researchers rarely present the methods used to standardize variable data. Nevertheless, different mathematical approaches are used to normalize the variables. Methodological approaches to the standardization of factors vary and are likely to transform variables between (-1) and (+1). OECD [39] reports several methods to normalize the factors: z-score, distance to a reference, ranking, logarithmic transformation, percentage of mean and min-max. Other authors have used weighting methods such as fuzzy function [43], comparison to threshold value [44], AHP [45] and expert judgement [23].

\subsubsection{Aggregation of Factors}

Factor aggregation consists of combining the normalized values of the selected factors into a composite index, and this can be done by either arithmetic or geometric aggregation. The aggregation formula may depend on the type of methods applied and the conceptualization of vulnerability. In some cases, factor aggregation requires a geographic information system (GIS) tool for a weighted superposition of parameters and a spatial representation of water resource vulnerability. In general, the so-called parametric methods of water resources vulnerability analysis use the following general forms of aggregation [1]:

$$
W V I=\frac{\sum_{i=1}^{n} r_{i} X_{i}}{\sum_{i=1}^{n} r_{i}}
$$

where $W V I$ is the water resources vulnerability index, $X_{i}$ is the normalized value of the $i$ th factor, and $r_{i}$ is the risk that this factor will increase the degree of vulnerability.

$$
V_{i}=\sum_{i=1}^{n} C_{i} * P_{i}
$$

where $V_{i}$ is the vulnerability of the water resource, $C_{i}$ is the ith normalized quantitative value of the observed data and $P_{i}$ is the weights of $i$ th factors [45, 46].

The forms of aggregation of physical modeling methods are generally based on a series of analytical and semi-analytical solutions of empirical equations such as advection-dispersion [47]. The forms of aggregation of statistical methods are often regression models or principal component analysis of standardized data [48, 49].

\subsection{Methodological Approaches to Water Vulnerability Assessment}

It is difficult to make an exhaustive inventory of all methods of water resources assessment; only a few examples of methods frequently found in the scientific literature on water resources can be given. Since the 1960s, most of the methods developed have focused on ground water vulnerabilities, particularly to pollution [7]. Margat [8] assessed, for the first time, the vulnerability of ground water to pollution by considering only three hypotheses: the vertical introduction of pollutants carried by infiltration waters, the spread of polluted water, and the persistence of pollution that depends on the ability of water to renew itself naturally. The method developed by Margat [8] is mainly a physical modeling method.

Albinet [9] used Margat's [8] work to develop the first vulnerability maps. Aller et al. [50] then developed, on behalf of the U.S. Environmental Protection Agency (US EPA), a method for assessing the vulnerability of groundwater to pollution called "DRASTIC" by selecting a number of intrinsic factors considered relevant. Since then, methods for assessing the vulnerability of water resources have been derived from DRASTIC, such as methods developed by Foster [51], Civita [52], and Doerfliger and Zwahlen [53]. Through review of the scientific literature, three main groups of methods for assessing the vulnerability of water resources are evident:

- Parametric methods or overlay and index 
methods;

- Process-based models or methods by physical modeling;

- Statistical methods.

The three methodological approaches to vulnerability assessment are indeed different in their conceptualization and the choice of factors as well as in their formulation. Zhang et al. [54] differentiate them as follows: (1) overlay or indexing methods combine specific physical characteristics that affect vulnerability, (2) process-based methods use mathematical models that approximate the behavior of substances in the subsurface and (3) statistical methods establish relationships with areas where contamination has occurred.

Masetti et al. [55] assume that parametric methods combine several physical factors influencing groundwater vulnerability and are weighted by expert opinion, while modeling methods are based on mathematical or analytical models to determine small-scale water contamination; and statistical methods are based on observation instead of expert opinion and combine physiographic and anthropogenic factors. The parametric methods are based on a multi-criteria analysis that includes social and physical factors [1, 28, 46]. Unlike statistical and modeling methods, parametric methods are closely dependent on the opinion of the experts in charge of the evaluation because of the arbitrary assignment of weights to the different parameters [56]. Depending on the contamination information observed in the area, statistical methods can be used to find the relationship between survey data and contamination factors [57]. The objective of statistical methods is, therefore, to identify the variables that are likely to define the probability of contamination of water resources [57]. Parametric methods are the most widely used because of their simplicity [55], but physical modeling methods are more elaborate than parametric and statistical methods [58]. Parametric methods have the advantage of involving all water sector stakeholders, and, therefore, integrate socio-economic, eco-environmental and physical factors. Physical modeling methods are based on assumptions verified by mathematical models, are generally applied to groundwater, and are generally used by hydrogeologists. Statistical methods consist in finding a correlation between observed contamination and environmental or social variables that may explain the contamination.

\section{Methods}

\subsection{Data Sources and Search Strategy}

This study used the Preferred Reporting Items for Systematic Reviews and Meta-Analyses (PRISMA) protocol [59] to select documents on water resources vulnerability assessment. Moher et al. [59] developed the method to examine a sample of articles by issuing predefined criteria for inclusion and exclusion of the documents to be analyzed to meet a specific objective. In this study, all articles were collected between December 2016 and May 2018 using the ScienceDirect and the Google Scholar databases.

For each database, previously defined keywords were used to collect articles that meet the expected goal. The ScienceDirect database is well organized and structured. For each search, the database asks for a keyword, name of the author, journal or book title, volume, issue, page, and proposes to make an advanced search in which a new window proposes to filter the search according to the date of publication and the type of articles (reviews, research articles, etc.). Google Scholar does not have all these features; it is based on a keyword search bar for the articles to appear. Only keywords in the English language were used to search for relevant articles.

\subsection{Inclusion and Exclusion Criteria}

The online literature search included all articles with "water vulnerability" or "water vulnerability assessment" or "water vulnerability index" titles. All articles highlighting a multidimensional or 
mono-dimensional analysis of vulnerability of water resources are included. An article is included only when its content deals in a practical way with the assessment of vulnerability, i.e., authors defined a set of water vulnerability factors and collected quantitative or qualitative data on the different factors to assess the vulnerability of water resources. Only articles assessing the vulnerability of water resources at local scale are included. Articles with titles such as "water vulnerability" that assess the water vulnerability at the intercountry level are excluded. Articles assessing the vulnerability of intercontinental water resources are also not considered. Finally, the analyzed documents are articles published in peer-reviewed journals and conference papers regardless of the date of publication and the country in which the study was conducted.

\subsection{Quality Appraisal of Articles}

To meet the quality requirements of the content, all screened articles were read and re-read. For each article, a quality assurance check was performed to insure that the authors have assessed the vulnerability of the water resources in a practical way, determine the method used, and determine the scale of application. To avoid a risk of bias in the analysis, the study did not include any intentional keywords that refer to a voluntary selection of a type of article. Once these conditions were met, the screened article was validated and included in the final analysis.

\section{Results and Discussion}

After in-depth studies of selected articles, all articles that address the vulnerability of water resources on the continental scale or that treat a part of a continent, such as Middle East and North Africa (MENA) region, were eliminated. At the end, articles were selected that address the assessment of water resources vulnerability at the national (country), regional, or municipal scale. Articles that address the vulnerability of water resources at a catchment scale are included even if this implies that several countries are involved, as long as the selected factors can be measured at the scale of a small watershed.

Fig. 1 presents the flow diagram of research protocol and selection of articles. The number of articles was 218 for the ScienceDirect database and 156 respectively for the Google Scholar database. After removing the duplicate articles and applying the inclusion and exclusion criteria, only 32 out of the 374 articles met the previously defined criteria.

\subsection{Description of Selected Articles}

The water resources vulnerability assessment is increasingly becoming a worldwide practice, as already mentioned by other researchers [4, 10, 22]. The selected articles come from all over the world: Asia, Africa, America, Europe and Australia. China (21.9\%), USA (9.4\%) and Canada (6.3\%) are the most prolific countries in publishing water resources vulnerability assessment studies (Table 1).

\subsection{Analysis of Water Resources Vulnerability Factors and Framework}

The definition and conceptualization of vulnerability are very important steps in a vulnerability assessment of water resources. Indeed, the setting up of the conceptual framework presenting the different components of vulnerability is based on the definition of vulnerability according to the objective of the study and the environmental problem addressed. From a conceptual framework that studies the interrelationships between the different components, indicators are chosen to assess the vulnerability of water resources. Winograd et al. [36] argue that there is not a universal set of indicators that are equally applicable in all cases and that the selection of indicators should be closely linked to the project objectives and the environmental issues addressed. Gain et al. [4] report that the vulnerability of water resources is defined and conceptualized with respect to physical, social, economic, environmental 


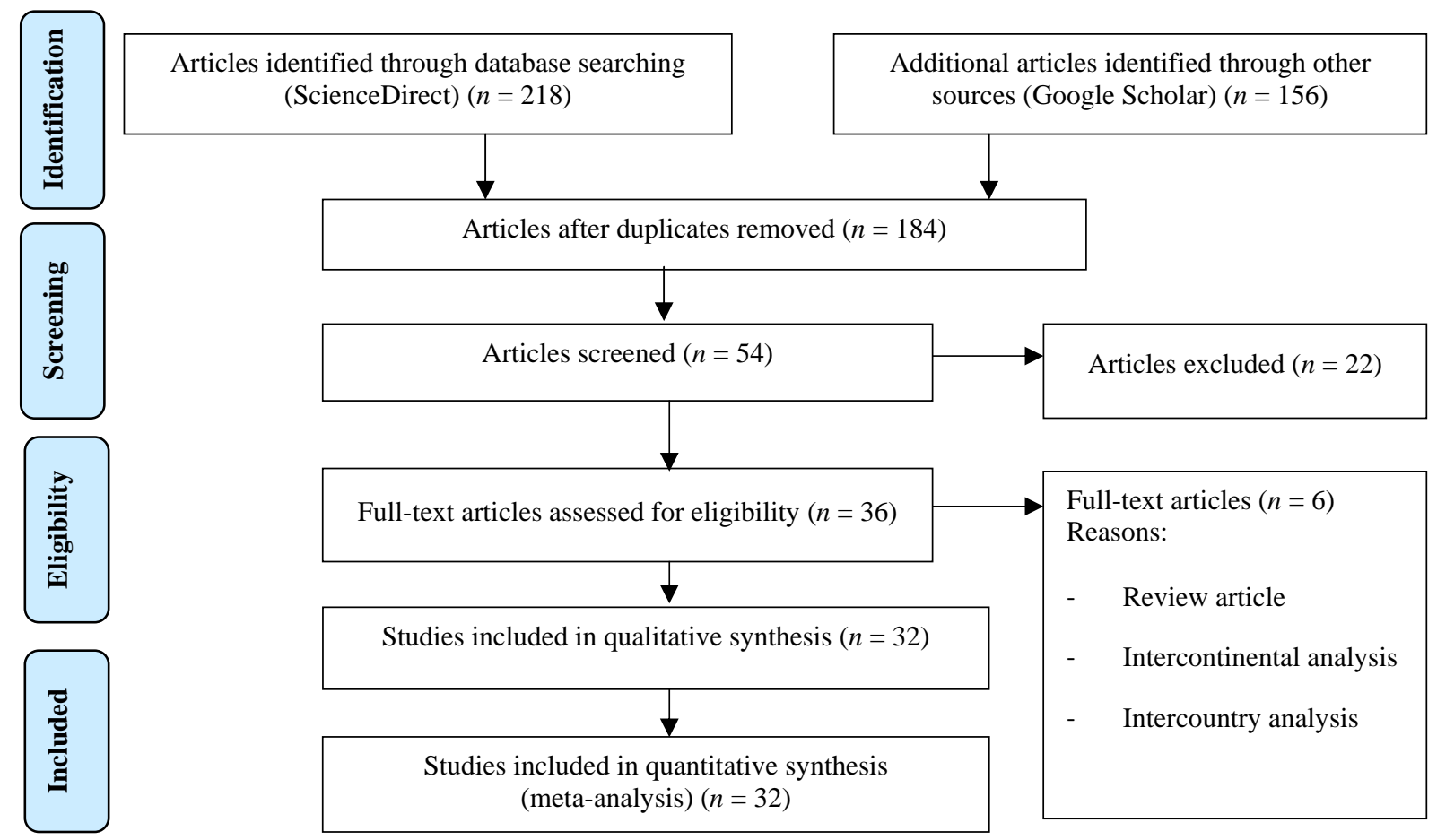

Fig. 1 Flow diagram of research protocol and selection of articles [59].

Table 1 Descriptive features of the 32 studies selected.

\begin{tabular}{|c|c|c|}
\hline Reference & Country & Scale \\
\hline Alessa et al. [28] & Canada & Community \\
\hline Anandhi et al. [10] & USA & Regional \\
\hline Aydi et al. [43] & Tunisia & Regional \\
\hline Baalousha [60] & Qatar & National \\
\hline Baki et al. [61] & Morocco & River basin \\
\hline Banton and Villeneuve [62] & USA & Municipality \\
\hline Boruff et al. [63] & Australia & Regional \\
\hline Bâr et al. [64] & Switzerland & Catchment \\
\hline Cai et al. [21] & China & National \\
\hline Chen et al. [65] & Taiwan & River basin \\
\hline Connell and Daele [47] & UK & Watershed \\
\hline Gain et al. [4] & Bangladesh & River basin \\
\hline Hamouda et al. [44] & Egypt & River basin \\
\hline Haryanto [66] & Indonesia & Provincial \\
\hline Javadi et al. [67] & Iran & River basin \\
\hline Jun et al. [68] & Korea & River basin \\
\hline Junior et al. [5] & Portugal & River basin \\
\hline Leone et al. [69] & Hungary & Watershed \\
\hline Masetti et al. [55] & Italy & Municipality \\
\hline Nobre et al. [70] & Brazil & Municipality \\
\hline Plummer et al. [22] & Canada & Community \\
\hline Ribeiro et al. [71] & Ecuador & Regional \\
\hline Shabbir and Ahmad [45] & Pakistan & Cities \\
\hline Shen et al. [23] & China & Metropolitan \\
\hline Srinivasan et al. [72] & India & Municipality \\
\hline
\end{tabular}


(Table 1 continued)

\begin{tabular}{lll}
\hline Reference & Country & Scale \\
\hline Sullivan [1] & South Africa & Basin/Watershed \\
Tesoriero and Voss [49] & China & River basin \\
Wang et al. [7] & China & Regional \\
Wang et al. [73] & China & Regional \\
Wu et al. [27] & China & River basin \\
Xia et al. [74] & China & River basin \\
Yanhui et al. [46] & China & River basin \\
\hline
\end{tabular}

and institutional features.

The results of the study show that authors used different factors to assess water resources vulnerability. Based on the names of the factors used in Füssel [25], Sullivan [1], Gain et al. [4] and Wang et al. [73], the factors are divided into five categories: physical factors (33.5\%), socio-economic factors (28.3\%), environmental or eco-environmental factors (25.1\%), institutions and governance factors (7.3\%) and infrastructure factors (5.8\%).

Physical Factors (64)_-(1) Mean annual rainfall, (2) Annual rainfall relative variability, (3) Annual mean temperature, (4) Water production $/ \mathrm{km}^{2}$, (5) Recharge of groundwater $/ \mathrm{km}^{2}$, (6) Drought index, (7) River flow, (8) Surface water, (9) River runoff, (10) Municipal supply yield, (11) Source diversity, (12) Permafrost risk, (13) Upstream modification, (14) Water resources variation, (15) Water resources scarcity, (16) Average annual runoff, (17) Average annual evapo-transpiration, (18) Wet spell length, (19) Maximum consecutive wet days, (20) Dry spell length, (21) Average dry spell length, (22) Maximum consecutive dry days, (23) Warm spell days, (24) Average warm spell days, (25) Maximum warm spell days, (26) Cold spell days, (27) Average cold spell days, (28) Number of cold spell days, (29) Maximum cold spell days, (30) Average maximum temperature, (31) Average minimum temperature, (32) Average temperature, (33) Standard precipitation index (SPI), (34) Average Euclidean distance to pipeline, (35) Average Euclidean distance to aquifer with allocation limit, (36) Flood index, (37) Groundwater exploitable yield, (38) Groundwater exploitation degree, (39) Low transmissivity and storage of aquifer, (40) Days per year when rainfall $=0$, (41) \% upstream area urbanized, (42) Aquifer type, (43) Depth to water table, (44) Slope, (45) Net groundwater recharge, (46) Soil media, (47) Topography, (48) Impact of the vadose zone, (49) Hydraulic conductivity, (50) Epikarst, (51) Protection cover, (52) Infiltration conditions, (53) Karst network, (54) Percent of country's territory under severe water stress, (55) Coefficient of variation of surface flow, (56) Arid lands index, (57) Water balance, (58) Geological profiles, (59) Average annual flood damage, (60) Annual maximum daily runoff (future), (61) Daily maximum runoff, (62) Water abundance, (63) Ground water recharge capacity and (64) Gradient.

Socio-Economic Factors (54)_-(1) Water resources per capita, (2) Water consumption per $10^{4}$ yuan GDP, (3) Water consumption per capita, (4) Water use plan change ratio, (5) Water supply and demand ratio, (6) Water resources development and utilization ratio, (7) Repetitive water use ratio of industry, (8) Amount of rice production (ton) a proxy of agricultural production, (9) Economic wealth of the population: “incidence of poverty”, (10) Traditional knowledge, (11) Subsistence values, (12) Social network diversity, (13) Perception of change, (14) Average population change, (15) Population density, (16) Percent of allocation limit currently available for future public or private use, (17) Total volume abstracted per year by public water supply utility, (18) Long-term sustainable abstraction for public water supply per year, (19) Index of relative socio-economic disadvantage, (20) Density of livestock, (21) Employment in industrial 
sectors as a percentage of total employment, (22) Growth rate in population, (23) Growth rate in number of livestock, (24) Growth rate in area cropped, (25) Growth rate in employment in industrial sectors, (26) Safe drinking water accessibility, (27) Improved sanitation accessibility, (28) Human development index (HDI), (29) Product domestic regional brut, (30) Technical capacity, (31) If the household uses tube well as a drinking water source, (32) If the household collects drinking water more than two times a day, (33) Percentage of vulnerable groups, (34) Increase in number of commercial establishments, (35) \% of employment from water-dependent sectors, (36) Mean annual rate of population growth, (37) National poverty rate, (38) Use of agricultural pesticides, (39) Use of fertilizers per hectare of agricultural land, (40) Labor force, (41) Scientists and engineers in research and development per million population, (42) Number of pumping station, (43) Number of vehicles, (44) Water qualification rate, (45) Water resource development \& utilization ratio, (46) Water utilization efficiency, (47) Water resource allocation, (48) Income per capita, (49) Regional water resources income, (50) System stability, (51) Water resource allocation rationality, (52) Western knowledge, (53) Residency time and (54) Community wealth.

Environmental or Eco-environmental Factors (48) - (1) Land development ratio, (2) Land use, (3) Fertilizer use intensity, (4) Pollution index of surface water, (5) Over extraction ratio of groundwater, (6) Surface ratio of soil erosion, (7) Water loss rate, (8) Disposal ratio of sewage, (9) Area forest cover at North-East India, (10) Aquatic habitat, (11) Terrestrial habitat, (12) Protected area status, (13) Irrigation coverage, (14) Sum of dam carryover storage and annual inflow, (15) Area of cleared land used for cropping, (16) Environmental water requirement, (17) Percentage of agricultural land, (18) Climate change, (19) Environmental pressure, (20) Environment, (21) Catchment area, (22) Average annual concentrations of PM2.5, (23) Average annual concentrations of
PM10, (24) Average annual concentrations of $\mathrm{SO}_{2}$, (25) Average annual concentrations of $\mathrm{NO}_{2}$, (26) Proximity to concentrated land use, (27) Urban area, (28) Cereals mariachi culture, (29) Forager culture where most of the livestock farming takes place, (30) Proximity to main roads, (31) Proximity to residential areas, (32) Proximity to rivers (m), (33) Nitrate-N concentrations, (34) Water quality index, (35) Irrigation water requirement ratio, (36) Share of treated wastewater by the public sewerage system, (37) Drinking water use efficiency, (38) Irrigation dependence, (39) Industrial organic pollutants per available freshwater in metric tons of biological oxygen demand (BOD) emissions per $\mathrm{km}^{3}$ of water, (40) Industrial environmental compliance, (41) Water physico-chemical parameters, (42) Status of water resources development, (43) Repetitive utilization degree of industrial water, (44) Impacts of land development on water resources, (45) Agricultural pollution intensity on water quality, (46) Degree of sewage disposal, (47) Water saving capacity of agriculture and (48) Wastewater treatment subsystem.

Institutions and Governance Factors (14) - (1) Perceived trend of composite water governance (numeric value between 0-1), (2) Water polities, (3) Water conflict, (4) Average official development assistance for water in \$/capita/year, (5) Existence of water quality standards for effluent discharges, (6) Minimum river water quality targets (Yes/No), (7) Research and development expenditure as \% of GDP, (8) Government effectiveness, (9) Political stability and absence of violence, (10) Access to improved water supply, (11) Access to sanitation, (12) Number of managers for flood damage prevention, (13) Water management level and (14) Regulating capacity of hydraulic engineering.

Infrastructure Factors (11) - (1) Water saving irrigation ratio, (2) Regulating power of hydraulic engineering, (3) Storage and release capacity of reservoir, (4) Hydroelectric installed capacity, (5) Treatment technology, (6) Total desalination 
production per year, (7) Pipeline density, (8) New water and sewer pipes, (9) Reservoirs and treatment plants, (10) Decrease in pipeline leakage and (11) Hydropower dependence.

More than 500 indicators (with duplicates) were used in the 32 selected articles. After removing the duplicates, 191 indicators were distributed among the five categories of factors. Physical factors are the most used in the assessment of water resource vulnerability, followed by Socio-economic factors, Eco-environmental factors, Institutional and Governance factors and Infrastructure factors.

For each reviewed manuscript, the focus was on the techniques used for the choice of indicators, the normalization method, and the weighting method (Table 2). A minimum of four indicators was used per study [74]; the maximum number of indicators was 106 [22], and the average number per study was approximately 16 indicators. The results show that the authors used several methods for the selection of indicators: participatory methods through questionnaires [63], the Delphi technique [28], LR [55], theoretical understanding of relationships (TUR) and statistical relationships [10], and empirical methods where the choice and the aggregation method of indicators have been imposed by the vulnerability assessment method applied.

The method used to normalize the selected indicators are various: the min-max method [68], fuzzy function [43], ranking by experts [10], comparison of the indicator value to threshold or a reference [46], standardized beta coefficients [63] and empirical method. The weighting method is generally based on expert opinion [1], participative approach with stakeholders [22], AHP [5], LR [4], Delphi technique [73] and empirical method [71].

Nowadays, more and more authors are conceptualizing the vulnerability of water resources in a holistic way. An author has assessed vulnerability in an integrated way if he has considered all five categories of factors. This study shows that almost half of the studies (47\%) considered all five categories of factors, 9.4\% considered four categories of factors, $6.3 \%$ considered three categories of factors, $28 \%$ used two types of factors and $9.4 \%$ considered only one category.

\subsection{Analysis of Water Resources Vulnerability Assessment Methodologies and Classification}

Several methodologic approaches have been conceptualized to assess water resources vulnerability. Table 3 presents the classification of selected studies according to the methodological approach used. In the literature, authors classified them in three main groups: process-based models [55, 75], parametric system methods [57, 75] or overlay and index methods [55] and statistical methods [55, 57]. Overlay and index methods combine different factors such as physical, environmental, socio-economic, infrastructure, and institution and governance factors that are weighted using a weighting technique approach according to their importance in influencing water vulnerability. Process-based methods are based on analytical or numerical models to assess the water vulnerability; they require detailed data and are generally used for small study areas [57]. Kumar et al. [76] and Masetti et al. [55] report that the statistical methods are based on observation and integrate information for a wide range of physiographic and anthropogenic factors to assess water vulnerability.

The frequency of use of assessment methods of water vulnerability used in the screening studies is as follows: overlay and index methods (59.4\%), process-based models (12.5\%), statistical methods (9.4\%), overlay and index methods plus process-based models (9.4\%), overlay and index methods plus statistical methods (6.3\%), and statistical methods plus process-based models (3.1\%). A wide number of these methods use the GIS to combine factors or to extract physical factors from satellite images. Researchers present the results of the vulnerability assessment on maps using GIS, in graphic or figure 
and table. GIS is an important tool in assessing the vulnerability of water resources with almost $60 \%$ of the studies using it at one stage of the assessment. Parametric methods or overlay and index methods are most commonly used in the assessment of water resource vulnerability [55] because of their simple applications [76], but process-based models are more elaborate [58]. Statistical methods are generally used to identify variables that are likely to define the probability of contamination of water resources [58].

Table 2 Techniques used by authors to select, normalize, and weight the water resources vulnerability indicators.

\begin{tabular}{|c|c|c|c|c|}
\hline Reference & No. of factors & Selection technique & Normalization technique & Weighting technique \\
\hline Alessa et al. [28] & 21 & Delphi & Delphi & Delphi \\
\hline Anandhi et al. [10] & 26 & STA & Ranking & Equal weight \\
\hline Aydi [43] & 8 & STA & Fuzzy function (in GIS) & AHP \\
\hline Baalousha [60] & 11 & DRASTIC & DRASTIC & DRASTIC \\
\hline Baki et al. [61] & 7 & DRASTIC & DRASTIC & DRASTIC \\
\hline $\begin{array}{l}\text { Banton and Villeneuve } \\
\text { [62] }\end{array}$ & 7 & DRASTIC (pesticide) & DRASTIC (pesticide) & DRASTIC (pesticide) \\
\hline Boruff et al. [63] & 23 & $\begin{array}{l}\text { Questionnaire from experts and } \\
\text { stakeholders }\end{array}$ & Standardized beta coefficients & NA \\
\hline Bâr et al. [64] & 12 & LR & NA & NA \\
\hline Cai et al. [21] & 6 & LR & NA & NA \\
\hline Chen et al. [65] & 11 & DRASTIC, LR & Empiric (DRASTIC) & DRASTIC \\
\hline Connell and Daele [47] & 4 & NA & NA & NA \\
\hline Gain et al. [4] & 7 & $\begin{array}{l}\text { Questionnaire from water } \\
\text { management experts }\end{array}$ & NA & Deductive approach, LR \\
\hline Hamouda et al. [44] & 31 & $\begin{array}{l}\text { TUR and statistical } \\
\text { relationships }\end{array}$ & $\begin{array}{l}\text { Comparison to threshold value } \\
\text { (ratio) }\end{array}$ & NA \\
\hline Haryanto [66] & 16 & LR & AHP & AHP \\
\hline Javadi et al. [67] & 10 & DRASTIC & DRASTIC & DRASTIC \\
\hline Jun et al. [68] & 18 & TUR & Min-max standardization & Expert opinion \\
\hline Junior et al. [5] & 15 & DRASTIC & Fuzzy pertinence functions & AHP \\
\hline Leone et al. [69] & 8 & DRASTIC & DRASTIC & DRASTIC \\
\hline Masetti et al. [55] & 9 & LR & NA & NA \\
\hline Nobre et al. [70] & 6 & DRASTIC & NA & Expert opinion \\
\hline Plummer et al. [22] & 106 & PA (survey, interview), LR & PA, comparison to threshold & PA \\
\hline Ribeiro et al. [71] & 5 & $\begin{array}{l}\text { DRASTIC (susceptibility index } \\
\text { derived) }\end{array}$ & NA & Delphi \\
\hline Shabbir and Ahmad [45] & 12 & LR & AHP & AHP \\
\hline Shen et al. [23] & 14 & LR & Ranking by experts & Ordered averaging \\
\hline Srinivasan et al. [72] & 15 & TUR & NA & NA \\
\hline Sullivan [1] & 16 & PA & NA & Expert opinion \\
\hline Tesoriero and Voss [49] & 11 & $\begin{array}{l}\text { Empiric (Washington State } \\
\text { Dept. of Health) }\end{array}$ & NA & NA \\
\hline Wang et al. [7] & 21 & TUR & CRV & AHP \\
\hline Wang et al. [73] & 21 & TUR & CRV & AHP \\
\hline Wu et al. [27] & 7 & TUR & NA & NA \\
\hline Xia et al. [74] & 4 & LR & NA & NA \\
\hline Yanhui et al. [46] & 15 & TUR & CRV & AHP \\
\hline
\end{tabular}

LR: literature review; AHP: analytic hierarchy process; CRV: comparison to a reference value (ratio); NA: not applicable; PA: participative approach; STA: system thinking approaches (inductive and deductive); TUR: theoretical understanding of relationships; DRASTIC: empiric-depth to water, net recharge, aquifer media, soil media, topography, impact of the zone media, hydraulic conductivity of the aquifer. 
Table 3 Classification of selected studies according to the methodology used.

\begin{tabular}{|c|c|c|c|c|c|}
\hline Reference & $\begin{array}{l}\text { Process-based } \\
\text { models }\end{array}$ & $\begin{array}{l}\text { Parametric system methods or } \\
\text { overlay and index methods }\end{array}$ & $\begin{array}{l}\text { Statistical } \\
\text { methods }\end{array}$ & GIS & $\begin{array}{l}\text { Table, graphic, } \\
\text { figure }\end{array}$ \\
\hline Alessa et al. [28] & & $\checkmark$ & & & $\checkmark$ \\
\hline Anandhi and Kannan [10] & & $\checkmark$ & & $\checkmark$ & $\checkmark$ \\
\hline Aydi et al. [43] & & $\checkmark$ & & $\checkmark$ & \\
\hline Baalousha [60] & & $\checkmark$ & & $\checkmark$ & \\
\hline Baki et al. [61] & & $\checkmark$ & & $\checkmark$ & \\
\hline Banton and Villeneuve [62] & $\checkmark$ & $\checkmark$ & & & $\checkmark$ \\
\hline Boruff et al. [63] & & $\checkmark$ & & $\checkmark$ & \\
\hline Bâr et al. [64] & $\checkmark$ & & & $\checkmark$ & \\
\hline Cai et al. [21] & & $\checkmark$ & & $\checkmark$ & \\
\hline Chen et al. [65] & & $\checkmark$ & $\checkmark$ & $\checkmark$ & $\checkmark$ \\
\hline Connell and Daele [47] & $\checkmark$ & & & & $\checkmark$ \\
\hline Gain et al. [4] & & $\checkmark$ & & & $\checkmark$ \\
\hline Hamouda et al. [44] & & $\checkmark$ & & & $\checkmark$ \\
\hline Haryanto [66] & & $\checkmark$ & & $\checkmark$ & \\
\hline Javadi et al. [67] & & $\checkmark$ & $\checkmark$ & $\checkmark$ & \\
\hline Jun et al. [68] & $\checkmark$ & & $\checkmark$ & & $\checkmark$ \\
\hline Junior et al. [5] & & $\checkmark$ & & $\checkmark$ & $\checkmark$ \\
\hline Leone et al. [69] & $\checkmark$ & $\checkmark$ & & & $\checkmark$ \\
\hline Masetti et al. [55] & & & $\checkmark$ & $\checkmark$ & $\checkmark$ \\
\hline Nobre et al. [70] & $\checkmark$ & $\checkmark$ & & $\checkmark$ & \\
\hline Plummer et al. [22] & & $\checkmark$ & & & $\checkmark$ \\
\hline Ribeiro et al. [71] & & $\checkmark$ & & $\checkmark$ & \\
\hline Shabbir and Ahmad [45] & & $\checkmark$ & & & $\checkmark$ \\
\hline Shen et al. [23] & $\checkmark$ & & & $\checkmark$ & $\checkmark$ \\
\hline Srinivasan et al. [72] & & $\checkmark$ & & $\checkmark$ & $\checkmark$ \\
\hline Sullivan [1] & & $\checkmark$ & & & $\checkmark$ \\
\hline Tesoriero and Voss [49] & & & $\checkmark$ & & $\checkmark$ \\
\hline Wang et al. [7] & $\checkmark$ & & & & $\checkmark$ \\
\hline Wang et al. [73] & & $\checkmark$ & & $\checkmark$ & \\
\hline Wu et al. [27] & & & $\checkmark$ & $\checkmark$ & $\checkmark$ \\
\hline Xia et al. [74] & & $\checkmark$ & & & $\checkmark$ \\
\hline Yanhui et al. [46] & & $\checkmark$ & & $\checkmark$ & $\checkmark$ \\
\hline
\end{tabular}

This study finds that authors can often combine these three groups of methods during a single assessment of water resource vulnerability.

\subsection{Recent Trend of Water Resources Vulnerability} Assessment

A few years ago, researchers [1, 4, 22] on water resources management expressed the need to develop tools for integrated assessment of water resources, that is, a holistic assessment that takes into account not only surface water but also ground water using the five categories of factors identified above. Wang et al. [73] also pointed out that since the 1960s most of the methods developed have focused on ground water vulnerabilities, and a few on surface waters have focused on the supply and demand balance. They suggest that the assessment of vulnerability must be closely linked to climate change and human activities. Gain et al. [4] noted that often the assessment of water resource vulnerability only incorporates the physical component of water and assumes that the assessment of the vulnerability of water resources must go 
through the integrated water resources management approach. The results of this study show that $40 \%$ of the studies were conducted only on ground water, $60 \%$ of selected studies (Table 4) used at least three categories of factors to address the vulnerability assessment of both ground water and surface water. Table 4 shows the combination of factor categories of water vulnerability per selected study.

Fig. 2 presents the trend in publication number of studies carrying out a holistic assessment of water vulnerability. The selection results provided studies published between 1989 and 2018. Between 2008 and
2018 there was at least one publication carrying out an integrated assessment of water resources from the years 2010 onwards. The integrated assessments used all categorizes of factors and included both ground water and surface water.

\subsection{Limitations}

In this LR, only articles published in English were included. Since, the articles were extracted from only two databases, this study is not an exhaustive analysis. However, it gives an embryonic idea of trends in methodological approaches to assess the vulnerability

Table 4 Studies and categories of factors considered in water vulnerability assessments.

\begin{tabular}{|c|c|c|c|c|c|}
\hline Reference & Physical factors & $\begin{array}{l}\text { Environmental or } \\
\text { eco-environmental factors }\end{array}$ & $\begin{array}{l}\text { Socio-economic } \\
\text { factors }\end{array}$ & $\begin{array}{l}\text { Infrastructure } \\
\text { factors }\end{array}$ & $\begin{array}{l}\text { Institutions and } \\
\text { governance factors }\end{array}$ \\
\hline Alessa et al. [28] & $\checkmark$ & $\checkmark$ & $\checkmark$ & $\checkmark$ & $\checkmark$ \\
\hline Anandhi and Kannan [10] & $\checkmark$ & $\checkmark$ & $\checkmark$ & $\checkmark$ & $\checkmark$ \\
\hline Aydi et al. [43] & $\checkmark$ & $\checkmark$ & & & \\
\hline Baalousha [60] & $\checkmark$ & $\checkmark$ & & & \\
\hline Baki et al. [61] & $\checkmark$ & $\checkmark$ & & & \\
\hline Banton and Villeneuve [62] & $\checkmark$ & $\checkmark$ & & & \\
\hline Boruff et al. [63] & $\checkmark$ & $\checkmark$ & $\checkmark$ & $\checkmark$ & $\checkmark$ \\
\hline Bâr et al. [64] & $\checkmark$ & $\checkmark$ & & $\checkmark$ & \\
\hline Cai et al. [21] & $\checkmark$ & $\checkmark$ & $\checkmark$ & $\checkmark$ & $\checkmark$ \\
\hline Chen et al. [65] & $\checkmark$ & $\checkmark$ & & & \\
\hline Connell and Daele [47] & $\checkmark$ & & & & \\
\hline Gain et al. [4] & $\checkmark$ & $\checkmark$ & $\checkmark$ & $\checkmark$ & $\checkmark$ \\
\hline Hamouda et al. [44] & $\checkmark$ & $\checkmark$ & $\checkmark$ & $\checkmark$ & $\checkmark$ \\
\hline Haryanto [66] & $\checkmark$ & $\checkmark$ & $\checkmark$ & $\checkmark$ & $\checkmark$ \\
\hline Javadi et al. [67] & $\checkmark$ & & & & \\
\hline Jun et al. [68] & $\checkmark$ & $\checkmark$ & $\checkmark$ & $\checkmark$ & $\checkmark$ \\
\hline Junior et al. [5] & $\checkmark$ & $\checkmark$ & $\checkmark$ & $\checkmark$ & $\checkmark$ \\
\hline Leone et al. [69] & $\checkmark$ & & & & \\
\hline Masetti et al. [55] & $\checkmark$ & $\checkmark$ & & & \\
\hline Nobre et al. [70] & $\checkmark$ & $\checkmark$ & & & \\
\hline Plummer et al. [22] & $\checkmark$ & $\checkmark$ & $\checkmark$ & $\checkmark$ & $\checkmark$ \\
\hline Ribeiro et al. [71] & $\checkmark$ & $\checkmark$ & & & \\
\hline Shabbir and Ahmad [45] & $\checkmark$ & $\checkmark$ & $\checkmark$ & & \\
\hline Shen et al. [23] & $\checkmark$ & $\checkmark$ & $\checkmark$ & $\checkmark$ & \\
\hline Srinivasan et al. [72] & $\checkmark$ & $\checkmark$ & $\checkmark$ & $\checkmark$ & $\checkmark$ \\
\hline Sullivan [1] & $\checkmark$ & $\checkmark$ & $\checkmark$ & $\checkmark$ & $\checkmark$ \\
\hline Tesoriero and Voss [49] & $\checkmark$ & $\checkmark$ & $\checkmark$ & $\checkmark$ & $\checkmark$ \\
\hline Wang et al. [7] & $\checkmark$ & $\checkmark$ & $\checkmark$ & $\checkmark$ & $\checkmark$ \\
\hline Wang et al. [73] & $\checkmark$ & $\checkmark$ & $\checkmark$ & $\checkmark$ & $\checkmark$ \\
\hline Wu et al. [27] & & $\checkmark$ & $\checkmark$ & & \\
\hline Xia et al. [74] & $\checkmark$ & $\checkmark$ & $\checkmark$ & $\checkmark$ & \\
\hline Yanhui et al. [46] & $\checkmark$ & $\checkmark$ & $\checkmark$ & $\checkmark$ & \\
\hline
\end{tabular}




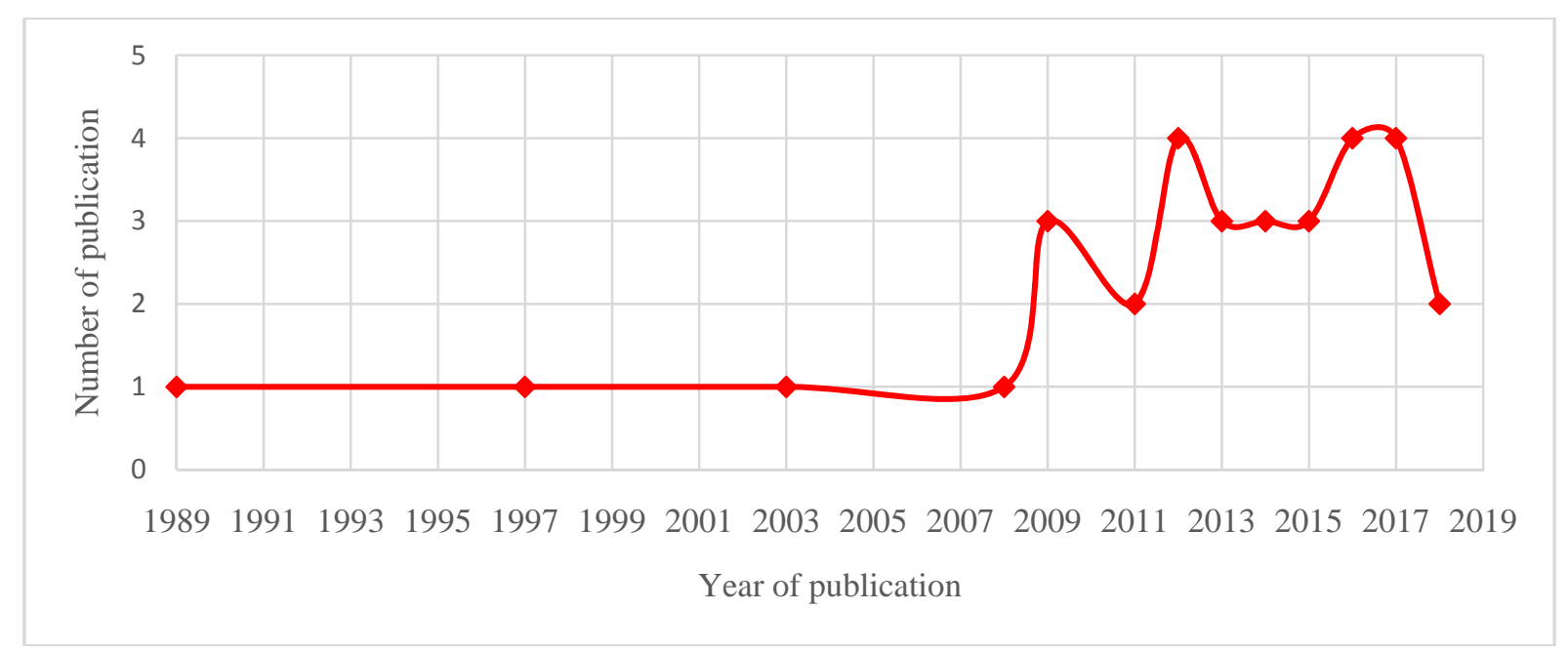

Fig. 2 Trend in number of publications with a holistic assessment of water vulnerability.

of water resources and the different factors used in the assessment.

\section{Conclusions}

This study examines methodological and factor trend of water vulnerability assessment at the local level in the international literature on water resources. Integrated assessments of water resources vulnerability are becoming increasingly common worldwide, and it has become essential for integrated water resources management. Nowadays, more and more researchers are conceptualizing the vulnerability of water resources in a holistic way. There is a need to know the factors of vulnerability of water resources used internationally to adapt them and undertake an integrated assessment of water resources to better combat the impacts of climate change. This work can help researchers and water managers get an idea of the trends in methodological approaches and the factors used in assessments of water resource vulnerabilities.

\section{Acknowledgments}

This study was undertaken as part of a doctorate at the Hassan II Institute of Agronomic and Veterinary Medicine in Rabat, Morocco. The Water and Soil Management Laboratory provided access to the databases.

\section{References}

[1] Sullivan, C. 2011. "Quantifying Water Vulnerability: A Multi-Dimensional Approach.” Stoch. Environ. Res. Risk Assess. 25 (4): 627-40.

[2] Shrestha, S., Kafle, R., and Pandey, V. P. 2016. "Evaluation of Index-Overlay Methods for Groundwater Vulnerability and Risk Assessment in Kathmandu Valley, Nepal.” Sci Total Environ. 575: 779-90.

[3] Mirauda, D., and Ostoich, M. 2011. "Surface Water Vulnerability Assessment Applying the Integrity Model as a Decision Support System for Quality Improvement.” Env. Imp. Assessm. Rev. 31 (3): 161-71.

[4] Gain, A. K., Giupponi, C., and Renaud, F. G. 2012. "Climate Change Adaptation and Vulnerability Assessment of Water Resources Systems in Developing Countries: A Generalized Framework and a Feasibility Study in Bangladesh.” Water 4 (2): 345-66.

[5] Junior, R. F. V., Varandas, S. G. P., Fernandes, L. F. S., and Pacheco, F. A. L. 2015. "Multi Criteria Analysis for the Monitoring of Aquifer Vulnerability: A Scientific Tool in Environmental Policy.” Env. Sci. \& Poli. 48 (C): 250-64.

[6] Jimenez-Cisneros, B. 1996. "Water Availability Index Based on Quality and Quantity: Its Application in Mexico.” Wat. Sci. Tech. 34 (12): 165-72.

[7] Wang, X., Ma, F., and Li, J. 2012. "Water Resources Vulnerability Assessment Based on the Parametric-System Method: A Case Study of the Zhangjiakou Region of Guanting Reservoir Basin, North China.” Proced. Env. Sci. 13 (3): 1204-12.

[8] Margat, J. 1968. "Vulnerability of Groundwater to Pollution Basics of Cartography.” Hydrogeology 68: 198. (in French)

[9] Albinet, M. 1971. "Application of Groundwater 
Vulnerability Maps to Pollution: Vulnerability of Captured Waters for Cities Food.” Hydrogeology 71: 325. (in French)

[10] Anandhi, A., and Kannan, N. 2017. "Vulnerability Assessment of Water Resources-Translating a Theoretical Concept to an Operational Framework Using Systems Thinking Approach in a Changing Climate: Case Study in Ogallala Aquifer.” J. of Hyd. 557: 460-74.

[11] Falkenmark, M., Lundqvist, J., and Widstrand, C. 1989. "Macro-scale Water Scarcity Requires Micro-scale Approaches-Aspects of Vulnerability in Semi-arid Development.” Nat. Res. Forum. 13 (4): 258-67.

[12] Gleick, P. 1996. "Basic Water Requirements for Human Activities: Meeting Basic Needs.” Water Interna. 21 (2): 83-92.

[13] Seckler, D., Amarasinghe, U., Molden, D., Silva, R., and Barker, R. 1998. World Water Demand and Supply, 1990 to 2025: Scenarios and Issues. Inter. Water Manag. Inst. Research Report 19.

[14] Meigh, J., Mckenzie, A., and Sene, K. 1999. "A Grid-Based Approach to Water Scarcity Estimates for Eastern and Southern Africa.” Water Resource Manag. 13 (2): 85-115.

[15] Plummer, R., De Loë, R., and Armitage, D. 2012. “A Systematic Review of Water Vulnerability Assessment Tools.” Water Resource Manag. 26 (15): 4327-46.

[16] Lawrence, P., Meigh, J., and Sullivan, C. 2002. “The Water Poverty Index: An International Comparison.” Nat. Res. Forum 27 (3): 189-99.

[17] Sullivan, C. 2002. "Calculating a Water Poverty Index." World Develop 30 (7): 1195-210.

[18] Sullivan, C., Meigh, J., Giacomello, A., Tediw, T., Lawrence, P., Samad, M., Mlote, S., Hutton, C., Allan, J., Schulze, R., Dlamini, D., Cosgrove, W., Priscoli, J., Gleick, P., Smout, I., Cobbing, J., Calow, R., Hunt, C., Hussain, A., Acreman, K. J., Malomo, S., Tate, E., O’Regan, D., Milner, S., and Steyl, I. 2003. "The Water Poverty Index: Development and Application at the Community Scale.” Nat. Res. Forum 27 (3): 189-99.

[19] Tran, L. T., O’Neill, R. V., Elizabeth, R., and Smith, E. R. 2012. "A Watershed-Based Method for Environmental Vulnerability Assessment with a Case Study of the Mid-Atlantic Region.” Env. Imp. Assessm. Rev. 34: 58-64.

[20] Vollmer, D., Regan, H. M., and Andelman, S. J. 2016. "Assessing the Sustainability of Freshwater Systems: A Critical Review of Composite Indicators.” J. Ambio. 45 (7): 765-80.

[21] Cai, J., Varis, O., and Yin, H. 2017. “China’s Water Resources Vulnerability: A Spatio-temporal Analysis during 2003-2013.” J. of Clean. Prod. 142 (4): 2901-10.

[22] Plummer, R., De Grosbois, D., Armitage, D., and De Loe,
R. 2013. "An Integrative Assessment of Water Vulnerability in First Nation Communities in Southern Ontario, Canada.” Glob. Env. Change 23 (4): 749-63.

[23] Shen, J., Lu, H., Zhang, Y., Song, X., and He, L. 2016. "Vulnerability Assessment of Urban Ecosystems Driven by Water Resources, Human Health and Atmospheric Environment.” J. of Hydrology 536: 457-70.

[24] Döll, P. 2009. "Vulnerability to the Impact of Climate Change on Renewable Groundwater Resources: A Global-Scale Assessment.” Envn. Res. Lett. 4 (3): 035006.

[25] Füssel, H. M. 2007. "Vulnerability: A Generally Applicable Conceptual Framework for Climate Change Research.” Glob. Env. Change 17 (2): 155-67.

[26] Kanakoudis, V., Tsitsifli, S., Papadopoulou, A., Curk, B. C., and Karleusa, B. 2016. "Estimating the Water Resources Vulnerability in the Adriatic Sea Region.” Procedia Eng. 162: 476-85.

[27] Wu, G., Li, L., Ahmad, S., Chen, X., and Pan, X. 2013. “A Dynamic Model for Vulnerability Assessment of Regional Water Resources in Arid Areas: A Case Study of Bayingolin, China.” Water Resource Manag. 27 (8): 3085-101.

[28] Alessa, L., Kliskey, A., Lammers, R., Arp, C., White, D., Hinzman, L., and Busey, R. 2008. “The Arctic Water Resource Vulnerability Index: An Integrated Assessment Tool for Community Resilience and Vulnerability with Respect to Freshwater.” Env. Manag. 42 (3): 523-41.

[29] Janssen, M., Schoon, M., Ke, W., and Borner, K. 2006. "Scholarly Networks on Resilience, Vulnerability and Adaptation within the Human Dimensions of Global Environmental Change.” Global Env. Change 16 (3): 240-52.

[30] Turner, B., Roger, E., Pamela, A., James, J., Robert, W., Lindsey, C., Noelle, E., Jeanne, X., Amy, L., Marybeth, L., Colin, P., Alexander, P., and Andrew, S. 2003. “A Framework for Vulnerability Analysis in Sustainability Science.” Proc. Nat. Acad. Sci. 100 (14): 8074-9.

[31] IPCC. 2018. Summary for Policymakers. https://archive.ipcc.ch/pdf/special-reports/sr15/sr15_spm _final.pdf.

[32] Hinkel, J. 2011. "Indicators of Vulnerability and Adaptive Capacity: Towards a Clarification of the Science-Policy Interface.” Global Env. Change 21 (1): 198-208.

[33] Birkmann, J. 2007. "Risk and Vulnerability Indicators at Different Scales: Applicability, Usefulness and Policy Implications.” Environmental Hazards 7 (1): 20-31.

[34] Allier, D., Vittecoq, B., and Mardhel, V. 2008. Assessment of the Intrinsic Vulnerability of Groundwater in Martinique. Bureau of Geological and Mining Research RP-56283-FR. (in French) 
[35] Sinan, M., Maslouhi, R., and Razack, M. 2003. "Use of GIS for the Characterization of Vulnerability and Sensitivity to Groundwater Pollution.” Presented at the 2nd FIG Regional Conference, Marrakech, Morocco, December 2-5, 2003. (in French)

[36] Winograd, M., Aguilar, M., Farrow, A., Segnestam, L., Linddal, M., and Dixon, J. 1999. Conceptual Framework to Develop and Use Water Indicators. CIAT/World Bank/UNEP Project. Rural Sustainability Indicators: Outlook for Central America.

[37] Hooper, B. P. 2003. "Integrated Water Resources Management and River Basin Governance.” JCWRE 126 (1): 12-20.

[38] Zarafshani, K., Sharafia, L., Hossein, A., Gholamhossein, H., Philippe, D. M., and Frank, W. 2014. "Drought Vulnerability Assessment: The Case of Wheat Farmers in Western Iran.” Global and Planetary Change 98-99 (6): 122-30.

[39] OECD. 2008. Handbook on Constructing Composite Indicators: Methodology and User Guide. http://www.oecd.org/els/soc/handbookonconstructingcom positeindicatorsmethodologyanduserguide.htm.

[40] Adger, W. 2006. "Vulnerability.” Global Env. Change 16: 268-81.

[41] Mazziotta, M., and Pareto A. 2013. "Methods for Constructing Composite Indices: One for All or All for One?” Italian J. Economics Demography Statistics 67 (2): 67-80. (in Italian)

[42] GIZ. 2014. The Vulnerability Sourcebook: Concept and Guidelines for Standardized Vulnerability Assessments. https://www.adelphi.de/en/publications/list.

[43] Aydi, A. 2018. "Evaluation of Groundwater Vulnerability to Pollution Using a GIS-Based Multi-criteria Decision Analysis.” Groundwater for Sustain. Develop 7: 204-11.

[44] Hamouda, M. A., Mohamed, M. N. E. D., and Moursy, F. I. 2009. "Vulnerability Assessment of Water Resources Systems in the Eastern Nile Basin.” Water Resource Manag. 23 (13): 2697-725.

[45] Shabbir, R., and Ahmad, S. S. 2015. "Water Resource Vulnerability Assessment in Rawalpindi and Islamabad, Pakistan Using Analytic Hierarchy Process (AHP).” J. of King Saud University Sci. 28 (4): 293-9.

[46] Yanhui, L., Liang, T., Jing, W., and Xianqiu, L. 2012. "Study on Water Resource Vulnerability Evaluation of Hani Terrace Core Area in Yuanyang.” Proceed. Earth and Planet. Sci. 5 (32): 268-74.

[47] Connell, L., and Daele, G. 2003. “A Quantitative Approach to Aquifer Vulnerability Mapping.” J. of Hydrology 276 (1-4): 71-88.

[48] Barradas, J. M., Fonseca, E. C., Da Silva, F., and Pereira, H. G. 1992. "Identification and Mapping of Pollution Indices Using a Multivariate Statistical Methodology,
Estarreja, Central Portugal.” Applied Geochemistry 7 (6): 563-72.

[49] Tesoriero, A., and Voss, F. 1997. "Predicting the Probability of Elevated Nitrated Concentration in the Puget Sound Basin: Implication for Aquifer Susceptibility and Vulnerability." USGS, Water Res. Div. 35 (6):1029-39.

[50] Aller, L., Bennett, T., Lehr, J. H., Petty, R. J., and Hackett, G. 1987. Drastic: A Standardized System for Evaluating Ground Water Pollution Potential Using Hydrogeologic Settings. NWWA/EPA Series, EPA-600/2-87-035.

[51] Foster, S. S. D. 1987. "Fundamental Concepts in Aquifer Vulnerability, Pollution Risk and Protection Strategy.” In Proceedings and Information No. 38 of the International Conference Held in the Netherlands, in 1987, TNO Committee on Hydrological Research, 36-86.

[52] Civita, M. 1994. The Cards of the Vulnerability of Aquifers to Pollution: Theory and Practice. PITAGORA (in Italian)

[53] Doerfliger, N., and Zwahlen, F. 1998. Groundwater Vulnerability Mapping in Karstic Regions (EPIK). Application to Groundwater Protection Zones. Practical guide. Swiss Agency for the Environment, Forests and Landscape.

[54] Zhang, R., Hamerlinck, J., Gloss, S., and Munn, L. 1996. "Determination of Nonpoint-Source Pollution Using GIS and Numerical Models.” J. of Env. Quality 25 (3): 411-8.

[55] Masetti, M., Sterlacchini, S., Ballabio, C., Sorichetta, A., and Poli, S. 2009. "Influence of Threshold Value in the Use of Statistical Methods for Ground Water Vulnerability Assessment.” Sci. of the Tot. Env. 407 (12): 3836-46.

[56] Ducommun, R. 2010. "Estimation and Mapping of Urban Groundwater Vulnerability.” Ph.D. thesis presented at the Faculty of Science of the University of Neuchâtel. University of Neuchâtel, Neuchâtel. (in French)

[57] Zhao, Y., and Pei, Y. 2012. "Risk Evaluation of Groundwater Pollution by Pesticides in China: A Short Review.” Procedia Environmental Sciences 13 (10): 1739-47.

[58] Kaur, R., and Rosin, K. 2007. Ground Water Vulnerability Assessment-Challenges and Opportunities. Division of Environmental Sciences, Indian Agricultural Research Institute.

[59] Moher, D., Liberati, A., Tetzlaff, J., and Altman, D. G. 2009. "Preferred Reporting Items for Systematic Reviews and Meta-Analyses: The PRISMA Statement.” Ann. Intern. Med. 151 (4): 264-9.

[60] Baalousha, H. M. 2016. "Groundwater Vulnerability Mapping of Qatar Aquifers.” J. of African Earth Sci. 124: 75-93.

[61] Baki, S., Hilali, M., Kacimi, I., Kassou, N., Nouiyti, N., 
and Bahassi, A. 2017. "Assessment of Groundwater Intrinsic Vulnerability to Pollution in the Pre-Saharan Areas-The Case of the Tafilalet Plain (Southeast Morocco).” Proceed. Earth and Planet. Sci. 17: 590-3.

[62] Banton, O., and Villeneuve, J.-P. 1989. "Evaluation of Groundwater Vulnerability to Pesticides: A Comparison between the Pesticide DRASTIC Index and the PRZM Leaching Quantities.” J. of Cont. Hydrology 4 (3): 285-96.

[63] Boruff, B., Biggs, E., Pauli, N., Callow, N., and Clifton, J. 2018. "Changing Water System Vulnerability in Western Australia’s Wheatbelt Region.” Appl. Geog. 91: 131-43.

[64] Bâr, R., Rouholahnejad, E., Rahman, K., Abbaspour, K. C., and Lehmann, A. 2015. "Climate Change and Agricultural Water Resources: A Vulnerability Assessment of the Black Sea Catchment.” Env. Sci. \& Polic. 46: 57-69.

[65] Chen, S.-K., Jang, C.-S., and Peng, Y.-H. 2013. "Developing a Probability-Based Model of Aquifer Vulnerability in an Agricultural Region.” J. of Hydrology 486: 494-504.

[66] Haryanto, E. 2014. Vulnerability Assessment of Water Resources to Climate Change in Bali Provinces, Indonesia. APCC Young Scientist Support Program.

[67] Javadi, S., Hashemy, S. M., Mohammadi, K., Howard, K. W. F., and Neshat, A. 2017. "Classification of Aquifer Vulnerability Using K-Means Cluster Analysis.” J. of Hydrology 549 (Suppl. C): 27-37.

[68] Jun, K. S., Chung, E.-S., Sung, J.-Y., and Lee, K. S. 2011. "Development of Spatial Water Resources Vulnerability Index Considering Climate Change Impacts.” Sci. Total Env. 409 (24): 5228-42.

[69] Leone, A., Ripa, M. N., Uricchio, V., Dea'k, J., and Vargay, Z. 2009. "Vulnerability and Risk Evaluation of
Agricultural Nitrogen Pollution for Hungary's Main Aquifer Using DRASTIC and GLEAMS Models.” J. of Env. Manag. 90 (10): 2969-78.

[70] Nobre, R. C. M., Filho, O. C. R., Mansur, W. J., Nobre, M. M. M., and Cosenza, C. A. N. 2007. "Groundwater Vulnerability and Risk Mapping Using GIS, Modeling and a Fuzzy Logic Tool.” J. of Cont. Hydrology 94 (3-4): 277-92.

[71] Ribeiro, L., Pindo, J. C., and Dominguez-Grand, L. 2016. "Assessment of Groundwater Vulnerability in the Daule Aquifer, Ecuador, Using the Susceptibility Index Method.” Sci. Total Env. 574: 1674-83.

[72] Srinivasan, V., Seto, K. C., Emerson, R., and Gorelick, S. M. 2013. "The Impact of Urbanization on Water Vulnerability: A Coupled Human-Environment System Approach for Chennai, India.” Glob. Env. Change 23 (1): 229-39.

[73] Wang, X., Ma, F., Li, C., and Zhu, J. 2015. “A Bayesian Method for Water Resources Vulnerability Assessment: A Case Study of the Zhangjiakou Region, North China.” Math. Prob. in Eng. 2015: 1-16.

[74] Xia, J., Chen, J., Weng, J., Yu, L., Qi, J., and Liao, Q. 2014. "Vulnerability of Water Resources and Its Spatial Heterogeneity in Haihe River Basin, China.” Chinese Geog. Sci. 24 (5): 525-39.

[75] Gogu, R., and Dassargues, A. 2000. "Current Trends and Future Challenges in Ground Water Vulnerability Assessment Using Overlay and Index Methods.” Env. Geol. 39 (6): 549-59.

[76] Kumar, P., Bansod, B. K. S., Debnath, S. K., Thakur, P. K., and Ghanshyama, C. 2015. "Index-Based Ground Water Vulnerability Mapping Models Using Hydrogeological Settings: A Critical Evaluation.” Env. Imp. Assessm. Rev. 51: 38-49. 